\title{
AWARENESS OF DISEASE AND SELF CARE AMONG HYPERTENSIVE PATIENTS ATTENDING TRIBHUVAN UNIVERSITY TEACHING HOSPITAL, KATHMANDU, NEPAL.
}

\author{
Buna Bhandari, Mahesh Bhattarai, Manjul Bhandari,and \\ Nilambar Jha
}

\begin{abstract}
:
Background: Hypertension (HTN) is a major risk factor for cardiovascular and renal diseases. The prevalence of hypertension has substantially increased during the past four decades. Information on prevalence as well as awareness regarding treatment and prevention of hypertension is scarce particularly in rural settings. The levels of awareness, treatment, and control of HTN vary between different countries and population groups. Objectives: The objective of this study was to find out the awareness of hypertensive patients about their own disease and self care. Methodology: Descriptive cross sectional study was conducted among 50 hypertensive patients who were admitted to Tribhuvan University Teaching Hospital (TUTH) and attended to medical OPD. Data was collected by using interview schedule by face to face interview method. Results: Among 50 hypertensive patients, $56 \%$ were aware about meaning of hypertension, $68 \%$ symptoms, $34 \%$ cause, $62 \%$ prognosis, and $62 \%$ complication of HTN. Likewise regarding self care, $70 \%$ were doing regular follow up, 92\% using regular medication, most of them (80\%) were not smoker and $84 \%$ were non alcoholic, and 74\% taking low fat and low salt diet. Conclusion: Study finding reflects many of them (56\%) had more than $50 \%$ of knowledge about the hypertension and more than half (54\%) were giving more than 50\% emphasis about their own self care.
\end{abstract}

Key words: Awareness, Hypertension, Control, Self care, Treatment

\section{Introduction:}

population ( 972 million) in 2000 , and the rates are expected to increase to $29.2 \%(1.56$ billion) by 2025 . In particular, the global burden of HTN is highest in developing countries, although the prevalence may be comparatively lower than that in developed countries. ${ }^{1}$ Cardiovascular disease is rapidly becoming a major cause of morbidity and mortality in developing countries throughout the world. ${ }^{2,3}$ Hypertension is one of the major risk factors leading to an increased risk of countries and population groups. HTN awareness among hypertensive individuals
Hypertension (HTN) affected $26.4 \%$ of the world's adult

stroke, myocardial infarction, end-stage renal disease, congestive heart failure and peripheral vascular disease. ${ }^{4}$ Despite the availability of effective agents, the control rate is low, with less than $5 \%$ of patients with hypertension having adequate control ${ }^{5}$ HTN can be effectively controlled by antihypertensive drug therapy, educational and lifestyle interventions. ${ }^{6,7}$ Unfortunately, the levels of awareness, treatment, and control of HTN vary between different

ranged from $25.2 \%$ to $75.0 \%$, whereas treatment ranged from $37.9 \%$ to $89.6 \%$ among 
those aware of their HTN status. ${ }^{8}$ However, little is known about the factors associated with awareness, treatment and control of HTN. Therefore, information on prevalence, awareness, treatment, and control and self care of hypertension in these poor resource settings is very scarce. The aim of the present study is to further elucidate the demographic factors that are associated with the awareness about disease and self care in order to better understand public awareness of the problem. This information is a pre-requisite to improvement of current clinical management.

\section{Methodology:}

Descriptive cross sectional study was conducted in the Medical Ward and Medical OPD of Tribhuvan University Teaching Hospital, Maharajgunj Kathmandu among the known cases of hypertension. A total of fifty hypertensive patients were included in the study following non probability purposive sampling method and adult patients with hypertension were included in the study whereas those who had developed complication of hypertension and severely ill patients were excluded from the study. Semi structured and structured interview schedule was used to collect necessary information using face to face interview technique by the researcher herself. For calculation of knowledge score, total nine questions regarding knowledge of hypertension and sixteen questions regarding self care was asked to all patients. Each affirmative answer was given one mark and total percentage was calculated based on their answers. Validity and reliability of the instrument was maintained by doing extensive literature review, consulting with experts and doing pretesting of the questionnaire. Collected data was checked, rechecked and edited at the end of data collection and coding and categorization was done. Data entry and analysis was done using Microsoft Excel and SPSS 11.5 version. Verbal consent was taken from the participants to participate in the study. Respondents were acknowledged for their participation in the study.

\section{Results:}

Among 50 hypertensive patient, many (44\%) of the respondents were among middle age group. Higher percentage were male (54\%) and (52\%) from rural area. More than half $(64 \%)$ were literate and $46 \%$ were suffering from hypertension between 1 to 5 yrs. (Table no. 1)

The awareness of hypertensive patient about their own disease is shown in Table 2, More than half $(56 \%)$ of them were aware about the meaning of hypertension and $58 \%$ thought that the most common age group susceptible for hypertension is middle age group (40 to 59yrs). Regarding the reason of hypertension 34\% thought that it is due to hereditary and stress. Another 34\% thought that it is due to all the reasons like age, obesity, smoking, alcoholism, stress and hereditary factors. Most of them (84\%) were aware about sign and symptoms of hypertension. Regarding prognosis, $62 \%$ of them thought it is controllable whereas $4 \%$ had no knowledge about it. And almost all patients were aware about control measure of hypertension and $62 \%$ of them knew about complications of hypertension. 
Table 1: Distribution of Socio demographic variables of respondents $(\mathrm{N}=50)$

\begin{tabular}{|c|c|c|c|}
\hline Characteristics & Categories & No & Percentage \\
\hline \multirow[t]{3}{*}{ Age in years } & $20-39$ & 10 & 20 \\
\hline & $40-59$ & 22 & 44 \\
\hline & 60 and above & 18 & 36 \\
\hline \multirow[t]{2}{*}{ Sex } & Male & 27 & 54 \\
\hline & Female & 23 & 46 \\
\hline \multirow[t]{2}{*}{ Residence } & Rural & 26 & 52 \\
\hline & Urban & 24 & 48 \\
\hline \multirow[t]{2}{*}{ Education Status } & Literate & 32 & 64 \\
\hline & Illiterate & 18 & 36 \\
\hline \multirow[t]{4}{*}{ Duration of hypertension } & Less than 1 years & 14 & 28 \\
\hline & $1-5$ years & 23 & 46 \\
\hline & 5- 10 years & 4 & 8 \\
\hline & More than 10 years & 9 & 18 \\
\hline
\end{tabular}

Regarding the habit of doing self care related to their own disease, $80 \%$ were not smoker and almost $84 \%$ did not have habit of taking alcohol (Table 3). Most of them (74\%) had habit of taking low salt and low fat diet. More than half (64\%) had habit of doing regular physical exercise and $62 \%$ were using different measure to reduce stress. Similarly $92 \%$ of them were taking their medication regularly but some of them $(10 \%)$ were changing their doses of their medication by themselves. Thirty percent of them were discontinuing their medicine anytime. It was very good practice that $70 \%$ of them were doing regular follow up, and $74 \%$ were checking their blood pressure regularly.

Maximum knowledge score about hypertension is $88.8 \%$ (8) was obtained by $10 \%(5)$ of respondents and minimum score was $22.2 \%$ (2) by $4 \%$ (2) respondents. Similarly the maximum score of awareness about self care was $87.5 \%$ (14) was obtained by $4 \%$ (2) of respondents and minimum score was $26.5 \%$ (4.25) which was obtained by $2 \%$ (4) of respondents 
Original article

Hypertension and Insight

Table 2: Distribution of respondents according to their knowledge about hypertension $(\mathrm{N}=\mathbf{5 0})$

\begin{tabular}{|c|c|c|c|}
\hline Knowledge & Responses & No & percentage \\
\hline \multirow[t]{2}{*}{ Meaning of hypertension } & Yes & 28 & 56 \\
\hline & No & 22 & 44 \\
\hline \multirow[t]{4}{*}{$\begin{array}{l}\text { Beliefs of most affected age } \\
\text { group }\end{array}$} & $20-39 y r s$ & 4 & 8 \\
\hline & $40-59 y r s$ & 29 & 58 \\
\hline & 60 yrs and above & 3 & 6 \\
\hline & No idea & 14 & 28 \\
\hline \multirow[t]{4}{*}{ Reason of hypertension* } & Overweight and old age & 11 & 22 \\
\hline & Smoking and alcoholism & 13 & 26 \\
\hline & Hereditary and stress & 17 & 34 \\
\hline & All of above & 17 & 34 \\
\hline \multirow[t]{4}{*}{$\begin{array}{l}\text { Sign and Symptoms of } \\
\text { Hypertension* }\end{array}$} & Dizziness and fatigue & 24 & 48 \\
\hline & Headache and palpitation & 32 & 68 \\
\hline & Flushing face and blurred vision & 13 & 26 \\
\hline & No idea & 8 & 16 \\
\hline \multirow[t]{4}{*}{ Prognosis } & Controllable & 31 & 62 \\
\hline & Curable & 9 & 18 \\
\hline & Not curable & 8 & 16 \\
\hline & No idea & 2 & 4 \\
\hline \multirow[t]{4}{*}{ Control Measures* } & Reducing weight and stress & 16 & 32 \\
\hline & Intake of low salt and low fat diet & 43 & 86 \\
\hline & By regular ex ercise & 23 & 46 \\
\hline & By medication & 26 & 52 \\
\hline \multirow[t]{2}{*}{ Complication of hypertension } & Know & 31 & 62 \\
\hline & Don’t know & 19 & 38 \\
\hline
\end{tabular}

$*=$ Multiple response answers 
Table 3: Distribution of respondents about habit of doing self care $(\mathrm{N}=50)$

\begin{tabular}{|c|c|c|c|}
\hline Self care practices & Responses & No & percentage \\
\hline \multirow[t]{2}{*}{ Smoking } & Yes & 10 & 20 \\
\hline & No & 40 & 80 \\
\hline \multirow[t]{2}{*}{ Alcoholism } & Yes & 8 & 16 \\
\hline & No & 42 & 84 \\
\hline \multirow[t]{3}{*}{ Dietary habit } & Low fat and salt diet & 37 & 74 \\
\hline & Low salt & 11 & 22 \\
\hline & Low fat & 2 & 4 \\
\hline \multirow[t]{2}{*}{ Physical Exercise } & Regular exercise & 32 & 64 \\
\hline & No regular exercise & 18 & 36 \\
\hline \multirow[t]{2}{*}{ Using Measure to reduce stress } & Yes & 31 & 62 \\
\hline & No & 19 & 38 \\
\hline \multirow[t]{2}{*}{ Taking medication } & Regularly & 46 & 92 \\
\hline & Irregularly & 4 & 8 \\
\hline \multirow[t]{2}{*}{ Changing dose by themselves } & Yes & 5 & 10 \\
\hline & No & 45 & 90 \\
\hline \multirow[t]{2}{*}{ Discontinuing medicine anytime } & Yes & 15 & 30 \\
\hline & No & 35 & 70 \\
\hline \multirow[t]{2}{*}{ Follow up } & Regular & 35 & 70 \\
\hline & Irregular & 15 & 30 \\
\hline \multirow[t]{2}{*}{ Monitoring blood pressure } & Regularly & 37 & 74 \\
\hline & Irregularly & 13 & 26 \\
\hline
\end{tabular}

\section{Discussion:}

Health care resources are scarce, and focusing investment in areas that would render the greatest benefits with the least cost needs to be identified. Morbidity and mortality from cardiovascular disease is high. Self-care can be defined as activities that a patient undertakes with the intention of improving health or preventing disease. Self-care for hypertension includes taking medicine as prescribed, monitoring blood pressure response to therapy, and adopting lifestyle recommendations increasing exercise, decreasing salt intake. Present study examined the level of awareness of hypertensive patients about their own disease and self care. The prevalence of hypertension was higher $44 \%$ among middle age groups (40$59 \mathrm{yrs})$ followed by young adults (20-39yrs) $36 \%$ whereas WHO study $1996^{9}$ showed $30 \%$ in above $30 \mathrm{yrs}$ and $14.19 \%$ among young adults. In a study in the productive age groups (30-49 years), $36.5 \%$ of the males were affected and $27.1 \%$ of the female affected. ${ }^{10}$ Our study showed male more suffered from hypertension $54 \%$ supported by other study ${ }^{11}$.

This study showed $56 \%$ of respondents were aware about hypertension which is higher than the study done in China $29.5 \%{ }^{12}$ and study done in Kathmandu valley $41.1 \%$. Main reason of hypertension given by respondents were hereditary and stress 34\% and another 34\% 


\section{Original article}

thought all the given factors i.e. overweight, old age, smoking, alcoholism, hereditary and stress. This study reflects control of hypertension can be done by taking low fat and low salt diet similar to the other studies which showed by doing regular exercise, changing healthy dietary habits. These healthy activities can control blood pressure of $25 \%$ of people and reduce by $77 \%$ by controlling weight and $35 \%$ by reduction of sodium in diet. ${ }^{13}$ Another study showed $80 \%$ of the patients knew they should limit their salt intake, only one third always avoided salty foods. ${ }^{14}$ Patients should be advised that excess salt ingestion will increase blood pressure. Salt restriction could make the difference between needing only 1 rather than 2 antihypertensive agents. Daily smokers were less likely to be aware of having HTN or being treated, whereas ex-smokers were more likely to be aware of their diagnosis. A possible explanation might be that some smokers quit smoking by themselves or followed by physicians' advice after detection of HTN.

Individuals who drank alcohol were also more likely to be untreated if they had HTN. ${ }^{15}$ Similarly this study shows $80 \%$ had no habits of smoking and $84 \%$ were not taking alcohol. Additionally, $25 \%$ of the patients did not appreciate the risk of alcohol use and 36\% believed they should drink a lot of fluids. ${ }^{14}$ The Joint National Committee 7 (JNC 7) also recommends that male patients consume not more than 2 alcoholic drinks per day and female patients no more than 1 drink per day. Limiting alcohol consumption may decrease (Systolic Blood Pressure) by 2 to $4 \mathrm{~mm} \mathrm{Hg}$. The JNC 7 recommends that patients involve themselves in aerobic exercise for at least 30 minutes per day on most days of the week. For approximately every 20 pounds of weight lost, it is believed that patients may reduce their SBP by 5 to $20 \mathrm{~mm}$ Hg. ${ }^{16}$ This study showed more than half $(64 \%)$ had habits of doing regular exercise supported

\section{Hypertension and Insight}

by other study which mention that exercise can help to reduce blood pressure and keep weight down. It is also a good stress reliever. ${ }^{17}$ This study found out $92 \%$ of them were taking their medication regularly and more than $90 \%$ never change their drug by themselves $70 \%$ of them did not discontinue their medication.

Despite the availability of effective treatment, over half of the patients being treated for hypertension drop out of care entirely within a year of diagnosis and of those who remain under medical supervision only about $50 \%$ take at least $80 \%$ of their prescribed medications. ${ }^{18}$ Similarly the present study showed that $70 \%$ of them were doing regular follow up, and $74 \%$ monitoring their blood pressure regularly and $40 \%$ were using blood pressure control measure if their blood pressure increases. So highest knowledge score about awareness of hypertension was $88.8 \%$ by $10 \%$ respondents and highest knowledge score of awareness of self care was $87.5 \%$ obtained by $4 \%$ respondents.

\section{Conclusion:}

The results of present study suggest that level of knowledge about disease and self care is good among the study population. The Seventh Report of the Joint National Committee on Prevention, Detection, Evaluation, and Treatment of High Blood Pressure states that self measurement of blood pressure may benefit patients by providing information on response to antihypertensive medication and improving adherence with therapy. The study also notes that the patient and clinician must agree on blood pressure goals. That patient motivation to adopt lifestyle changes and take prescribed medication improves when patients have positive experiences. Study suggests that there should be more research to find out new strategies to tackle these issues of awareness and self care about Hypertension. 


\section{References:}

1. Kearney PM, Whelton M, Reynolds K, Muntner P, Whelton PK, He J. Global burden of hypertension: analysis of worldwide data. Lancet 2005; 365:217-223.

2. Murray CJ, and Lopez AD. Alternative projections of mortality and disability by cause 1990-2020: Global Burden of Disease Study. Lancet 1997; 349:1498-1504.

3. Fuentes R, LImaniemi N, Laurikainen E, Tuomilehto J, Nissinen A. Hypertension in developing economies: a review of population-based studies carried out from 1980 to 1998 . J Hypertens 2000; 18:521-529.

4. Steyn K, Gaziano TA, Bradshaw D, Laubscher R, Fourie J. Hypertension in South African adults: results from the demographic and health survey, 1998. J Hypertens 2001; 19:1717-1725.

5. PRC National Blood Pressure Survey Cooperative Group. Hypertension Prevalence and the Status of People Awareness, Treatment, and Control in China: A national-wide survey in 1991. Chinese J Hypertens 1995; 3 (suppl):S14-S18.

6. Machado M, Bajcar J, Guzzo GC, Einarson TR. Sensitivity of patient outcomes to pharmacist interventions. Part II: Systematic review and meta-analysis in hypertension management. Ann pharmacotherapy, 2007; 41:1770-1781.

7. Fahey T, Schroeder K, Ebrahim S. Educational and organizational interventions used to improve the management of hypertension in primary care: a systematic review. Br J Gen Pract 2005; 55:875-882.

\section{Kearney PM, Whelton M, Reynolds K,} Whelton PK, He J. Worldwide prevalence of hypertension: a systematic review. J Hypertens 2004; 22:11-19.

9. The WHO report " Hypertension
Control",1996 pp 30-33

10. Prasanth TS, Vijayakumar K. Prevalence of Systemic Hypertension among the rural residents of Kerala. Calicut Medical Journal 2008; 6(3):e4.

11. Badhu BP,shresthaJK. Hypertension patient in eye OPD, TUTH. Journal of the IOM.1998; pp 188-192

12. Guang-Hui Dong†, Zhao-Qing Sun. Prevalence, awareness, treatment $\&$ control of hypertension in rural Liaoning province, China. Indian J Med Res 128, August 2008, pp 122-127

13. Onta M. Hypertension: AS tricking time bomb"Journal of Nursing "vol 1;1998:pp16-18

14. Hanyu Ni, Deirdre Nauman, Donna Burgess, Kendra Wise; Kathy Crispell, Ray E. Hershberger. Factors Influencing Knowledge of and Adherence to Self-care among Patients With Heart Failure. Arch Intern Med. 1999;159:1613-1619.

15. Yi Wua, E. Shyong Tai et.al. Risk factors associated with hypertension awareness, treatment, and control in a multi-ethnic Asian population. Journal of Hypertension 2009, 27:190-197

16. Joint National Committee, the $7^{\text {th }}$ report of the joint national Committee on detection, Evaluation and treatment of high bold pressure. Archives of internal Medicine 1993,153:154-18

17. T Diane. Leaflet: Hypertension - self help measures. Steyning Health Centre; October : 2003

18. Sackett DL. Randomized clinical trial of strategies for improving medication compliance in primary hypertension. Lancet, 1975; 1:1205-1207.

Correspondance address: Buna Bhandari Bhattarai, Lecturer, Department of Community MedicineNobel Medical College and Teaching Hospital, Biratnagar, Nepal. E-mail: bhbuna@gmail.com, Cell. Phone: 9842037499 